\title{
Ambidexterity in the supply chain: studying the apparel industry
}

\section{David Güemes-Castorena* and Brenda C. Ruiz-Monroy}

Department of Industrial Engineering, School of Engineering and Sciences, Tecnologico de Monterrey, Ave. Eugenio Garza Sada 2501, Monterrey, NL, 64849, Mexico

Email: guemes@tec.mx

Email: bcruizm@gmail.com

${ }^{*}$ Corresponding author

\begin{abstract}
Some decades ago, the concept of 'ambidexterity' was introduced in the theory and practice of organisation management, but only recently applied to the management of the entire supply chain. Our goals in this paper are to propose a definition for Ambidextrous supply chains in the field of apparel and to study the three leaders of the industry and identify if they balance their supply chain archetypes in their way to Ambidexterity. The apparel industry is one of the most global and fluctuating industries in the world, and apparel supply chains play a strategic role in the growth of the industry and permanency of the brands through end-consumer responsiveness. An ambidextrous supply chain refers to the ability to maintain daily operations excellence while looking for constant innovation and the ability to keep balance. This balance might be achieved through an ambidextrous supply chain. The three studied cases show how organisations can achieve ambidexterity by managing trade-offs latent in this industry.
\end{abstract}

Keywords: ambidexterity; supply chain archetypes; apparel industry; innovation process; strategic management; case study; supply chain trade-offs; fast archetype; efficient archetype; agile archetype.

Reference to this paper should be made as follows: Güemes-Castorena, D. and Ruiz-Monroy, B.C. (2020) 'Ambidexterity in the supply chain: studying the apparel industry', Int. J. Agile Systems and Management, Vol. 13, No. 2, pp.130-158.

Biographical notes: David Güemes-Castorena is a Full Professor of Technology and Innovation Management at Tecnologico de Monterrey. He received his DSc from The George Washington University. His research interest involves technological strategy and applied technological foresight. Currently, he is a Visiting Scholar at the MIT Sloan School of Management, working on regional innovation systems.

Brenda C. Ruiz-Monroy earned her MSc from Tecnologico de Monterrey. Since then, she has pursued her professional career across different e-tailer companies. This paper is partly the work of her thesis. 
This paper is a revised and expanded version of a paper entitled 'Balancing supply chain archetypes and ambidexterity in the apparel industry' presented at 2017 PICMET Portland International Center for Management of Engineering and Technology, Portland, OR, USA, 9-13 July, 2017.

\section{Introduction}

Supply chains (SC) play a strategic role in the growth of the industry and permanency of the brands through responsiveness with the end consumer, which results in a competitive advantage in the apparel industry. The estimated sales for this global industry came around US\$ 755 billion in 2010 (Kim, 2013) and are becoming increasingly complex and dynamic precisely because decisions turned global (Brun and Castelli, 2008). Another factor is that there are too many players from raw material suppliers to retail channels in the global SC. Retailers must not only balance returns on assets, growth, and inventory turns but also develop strategic approaches in collaboration with their SC partners to drive demand (Ganesan et al., 2009).

Also, the fashion consumer is becoming more discerning and demanding (Anbanandam et al., 2011), with changing fast requirements, known as fickle demand (Kim, 2013), and high-impulse purchase attitude, so availability becomes crucial. Therefore, the field of competition is switching towards a demand-driven SC (Brun and Castelli, 2008). The whole life cycle in the apparel industry shrinks rapidly, making it more challenging to achieve an appropriate level of responsiveness (Kim, 2013). In pursuit of competitive advantage, many firms turn their looks to their SC to build value networks and to develop collaborative relationships (Chiu, 2014). For the retail firms, it is determinant to isolate how SC decisions influence the overall retailer performance and the key marketing functions of brands, relationships, and innovation (Ganesan et al., 2009). Managers through the SC play essential roles in creating, maintaining and growing these relationships with different participants; they must share complex knowledge that helps to manage innovation, and simultaneously exploit their today's capabilities; this quality was defined some decades ago as ambidexterity.

Researchers have studied ambidextrous practices since effectively coordinating activities and functions has become one of the top priorities by fashion companies (Kim, 2013). These coordinated functions may be either exploitation, exploration, or both. In other words, it also refers to a permanent condition of balance, and this balance is extended to the SC strategy or SC archetype, which is the design pattern of the SC that defines the key factors of the business framework.

The specific objective of this study was to propose a definition for Ambidextrous $S C$ in the retail business focusing in the field of apparel and characterising which of SC archetypes are the three leaders of the industry balancing in the way to Ambidexterity.

\section{Theoretical framework}

The fashion industry is one of the most global businesses in the world (Abernathy et al., 2006). Countries like China, India, Pakistan, and Bangladesh are gaining their share in the global apparel market and are known as lower-cost labour countries to manufacturing 
(Kumar, 2008). Apparel wear is the final product of apparel SC (Cao, 2008). The trends constitute the principal added value of companies, so they renew, according to shorter cycles, the products put on the market. However, the trends are not enough, for companies to stand out from one to another, the style and value creation, according to logistical responsiveness are also necessary (Dari and Paché, 2013). It is imperative for the apparel industry to raise the responding speed of SC for the promotion of sales (Zhang, 2008b). Shorter collections and multiplication of product typologies (permanent, seasonal), are significant results of this market-driven strategy (Dari and Paché, 2013).

Firms in the fashion apparel industry are increasingly embracing the "fast fashion" retail philosophy system that combines short production and lead times (responsiveness), and highly fashionable, 'trendy' product design. Short cycles allow companies to stick to the customer's desires (pull) and to provoke new desires (push) (Dari and Paché, 2013). The most significant difficulty any apparel company encounters is managing demand uncertainty and controlling strategic consumer behaviours (consumers' propensity to delay purchase intentionally until a sale occurs). Fast fashion retailers, however, have overcome these challenges by supplying the small quantities of the latest fashion with agility, which has resulted in profitable revenue gains (Byoungho et al., 2012).

Meichtry describes how some firms are attempting to focus on design and develop trendier products without reducing their production lead times because of the logistical and cultural difficulties that can accompany drastically redesigning the supply network. In the textile/apparel industry, the firm owners generally coordinate the SC (Meichtry, 2007; Cao, 2008). Fast fashion is a business model tailor-made for the multi-channel 'I want it now' internet-driven buyer of today. It offers significant business value to a range of retail companies whose product cycles are accelerating and influenced by celebrities, luxury brands, and media hype. Accordingly, fast fashion SCs are different, characterised by significantly shorter cycles from design to delivery, often in three to six weeks. Frequent new product's flow that moves away from traditional two to four seasons per year, intense focus on style-colour depth instead of product line breadth, product as traffic driver rather than advertising, and a sourcing mix for flexibility and speed vs. cost alone also characterise fast fashion SC (Thorbeck, 2014).

\subsection{The apparel supply chain}

When dealing with a product characterised by a long lifecycle, efficiency should be pursued. In contrast, the SC should be extremely reactive for products staying on the market for a short period as fashion products (Brun and Castelli, 2008). The fashion supply chain (FSC) incorporates the flow of products, services, money, and information among suppliers, manufacturers, distributors, and retailers (Ngai et al., 2014). It has a focal firm that is the fashion company, which deals with numerous supplying functions or companies in the upstream and quite a few retailing alternatives or partners in the downstream (Kim, 2013).

Many supporting industries are related; purchasing and supplying are complicated, and the enterprise information system has too much information from different data sources (Yan et al., 2009; Mustafid et al., 2018). Ngai et al. (2014) divide the textile and apparel SC into three sectors: textile production, apparel manufacture, and distribution/sales. The control of physical distribution is undoubtedly essential to link the factories to the selling points, via a network of warehouses. However, it is vital to 
synchronise downstream logistics with the manufacturing planning and, upstream the supply of raw material and components (Dari and Paché, 2013).

The entities in clothing supply networks include, among others, the retailers, distributors, logistics and warehousing companies, designers, merchandisers, yarn, fabric and trims producers, garment manufacturers, and embellishment service providers (e.g., embroidery, decorative attachments, printing, washing) (MacCarthy and Jayarathne, 2013). Demand for short-life-cycle products or fashion goods is tough to forecast. Retailers and firms chronically suffer from costly markdowns (price reductions to move merchandise unsold at full price) and stock-outs (lost sales due to sellouts of popular styles). One strategy for responding to industry volatility and complexity (van Dijk, 2013) to master product speed, cost, and flexibility (Stevenson, 2013) across the entire enterprise supply network through a rapidly transformed and collaborative SC (Thorbeck, 2014) is the SC ambidexterity, for example.

\subsection{State-of-the-art: ambidextrous supply chain}

Interfirm research and development (R\&D) collaboration along the SC represents a common response to competitive pressures (Chiu, 2014) and also helps to be effective in matching demand with supply (Simatupang and Sridharan, 2002); the mismatch between supply and demand becomes costlier as compared to production costs, especially in an apparel SC with short life-cycle products (Simatupang and Sridharan, 2002).

Ambidextrous SC strategy from a manufacturer's perspective is a manufacturing firm's strategic managerial choice to simultaneously operationalise exploitation within SC management as the set of practices that refine and extend existing skills and resources to achieve lower costs and reliability. In contrast, exploration means practice to develop new SC competencies through experimentation and acquisition of new knowledge and resources within SC relationships (Kristal et al., 2010). Any ambidexterity model should consider that the actual environment of innovation is networked and involve several actors beyond the boundaries of the organisation. Companies can benefit from ambidexterity not only within the firm itself but also in an SC context (Blome et al., 2013). A company can strengthen its ambidexterity by involving a diverse body of collaborators in innovation processes (Kauppila, 2007).

\subsubsection{Supply chain domains}

When defining their collaborative strategies, managers frequently mention two specific domains of SC portfolio that balance and assist exploration and exploitation: the first is supplier diversity, which describes the extent to which firms' SC portfolios cover a diverse set of suppliers and get more-diverse expertise. However, the higher the number of simultaneous suppliers the firm has, the lesser the knowledge transfer. The second is repeated partnerships, which describe how much firms engage in different SC collaborations with the same partners, enabling the transfer of more complex knowledge.

However, exploring requires pursuing new knowledge; frequent and repeated collaborations with the same suppliers may not provide diverse, innovative, and flexible knowledge to a firm over the long term. While previous studies have focused on ambidextrous in one firm, ambidextrous in the SC (ASC) configures the value of an SC portfolio, highlighting the relationship between interfirm collaboration and exploration and exploitation activities (Chiu, 2014). Some metrics have been developed to evaluate 
the lean and agile SC for the manufacturing industries (Aravind Raj et al., 2018); other researchers have classified the firms of the textile-apparel-retail SC network based on their level of SC agility and test the differences in firms' performance across the clusters, but they have not been analysed from the innovation perspective (Jakhar and Barua, 2013).

\subsubsection{Managing supplier portfolio}

$\mathrm{SC}$ innovations ideally require closer relationships with their suppliers, particularly if the supplier provides input to the innovation activities of the firm (Aoki and Aoki, 2014). Chiu (2014) writes that innovation in the form of either exploration or exploitation activities needs the inflow of knowledge from an SC portfolio, but has a threshold level at which focal firms benefit from external collaborative agreements. Managers should consider the diversity of configuration and familiarity of knowledge flow within this SC portfolio. For Chiu (2014), the ASC is the deployment of the value of two SC portfolio characteristics: supplier diversity and repeated partnerships clarifying the relationship between interfirm collaboration with the exploration and exploitation activities. SC portfolio impacts both in the use of external knowledge and managing knowledge transfer to maintain exploration and exploitation flexibility.

Exploitation is interpreted as a repeated collaboration with the same suppliers which enables the transfer and integration of tactical and complex knowledge and helps firms to specialise technologically (Chiu, 2014), but close collaboration may increase the risk of lock-in with novel technologies - including information technologies (Mavengere, 2013). Contrastively, supplier diversity stimulates more exploration since the diverse technologies, and external knowledge helps firms to experiment with novel technologies and stimulate different capabilities; hence, a diverse set of suppliers facilitates different types of expertise. Another way to manage the SC portfolio is through structural separation (O'Reilly III and Tushman, 2004), which is an effective way to acquire ambidexterity, and it means to strategically segment suppliers and manage them differently to capture simultaneously multiple benefits.

Furthermore, it is also essential to focus on the choice of an appropriate governance mechanism in buyer-supplier relationships, which may be contractual or relational. For Blome et al. (2013), an ambidextrous SC is the simultaneous pursuit of both relational (informal, self-enforcing) and contractual (formal and hard negotiations) governance elements like the achievement of innovation and cost performance, in the buying organisation. Both dimensions, relational and contractual governance, are necessary to build long-term and reciprocal SC partners-relationship. For its part, the contractual approach favours exploitation due to its objective to minimise cost via efficiency gains. On the other hand, the relational approach is in favour of exploration, to take advantage of relational aspects, reciprocity, and flexibility, which can include information sharing for the further, joint exploration of new business opportunities. Then, the combination of relational and contractual governance, which has been suggested to be complementary in achieving impact on innovation and cost performance, can enable a competitive advantage in rising demand uncertainty and product complexity. These last concepts are fashion industry constants (Blome et al., 2013). 


\subsubsection{Knowledge in the SC}

Firms use two types of value chains, the exploitation, and the exploration network. The first one enhances current business and incremental innovations by rapidly circulating explicit knowledge. The alignment for the relationships in this first type of network is vertical, an arm-length collaboration, for example, collaboration with customers. The second chain seeks to enhance future business and radical innovations through circulating tacit knowledge. It has intimate and horizontal relationships to collaborate in the interfirm project, for example, joint R\&D (Kauppila, 2007). Integrating both types of value chain holistically continues to be a challenge (Moynian and Dai, 2011).

An ambidextrous SC can also be understood as a viable strategic choice by which manufacturers can leverage sources of external SC knowledge to build internal competencies and capabilities that is the ability to excel simultaneously on competitive capabilities of quality, delivery, flexibility, cost, and in turn, on business performance. In this context, exploitation goes for internalising and combining the existing knowledge bases to refine current processes and technologies within SC management, and exploration goes for knowledge creation within organisations (Kristal et al., 2010). In the same vein, Hernandez-Espallardo et al. propose that for a firm, learning capacity is a critical factor for its innovation and competitiveness (Hernández-Espallardo et al., 2011). They consider that there are three different types of knowledge-related issues in inter-firm relationships:

- $\quad$ knowledge from distributors (about products, technology, markets)

- the learning about collaborating with each distributor as the relationship evolves

- the firm's knowledge about managing distributors.

\subsubsection{Context and time terms}

Exploration and exploitation may be conceptualised under three dimensions

- $\quad$ supply

- demand

- geographic space.

In a settle down industry, context firms exploit supply-side and explore spatial and demand while in a fast-dynamic industry context (such as the fashion's) firms must exploit demand and geographic space (Sidhu et al., 2007). Correspondingly, Im and Rai (2008) define the contextual ambidexterity as the behavioural capacity of a long-term inter-organisational relationship to allow for the simultaneous pursuit of alignment and adaptability: exploit alignment of the objectives for improvement and explore adaptability of the objectives for innovation. Furthermore, an SC requires having two temporal orientations (the present and the future) and demand advancement on multiple capabilities to prepare for today and tomorrow's changing competitive landscapes. The construct of combinative competitive capabilities indicates a paradigmatic departure from the classical operations strategy literature that contends firms should trade-off their individual competitive capabilities, for example, cost vs. quality (Kristal et al., 2010). 


\subsubsection{Advantages of ambidexterity in the management of the supply chain}

Some of the advantages of an ambidexterity SC management (SCM) are

- $\quad$ value creation

- partners' satisfaction

- business performance

which are described next.

\subsubsection{Value creation}

A diverse supplier base and deep familiarity with individual suppliers stimulate firms to make exploration and exploitation activities. Collaboration with suppliers can increase value creation by expanding the availability and use of relevant knowledge. Firms may incorporate supplier expertise and perspective to improve their skills (exploitation) or create innovations (exploration) (Chiu, 2014).

\subsubsection{Partners' satisfaction}

An ambidextrous SC is intended to manage cooperative relationship portfolios to gain access to resources across the various phases of their value chain and to gain resource security provided by partners. Thus, an ambidextrous SC may be defined as the relationship between exploitation and exploration from portfolio members and SC partner satisfaction. For exploitation, it is assumed that the partner is using the resources, abilities, and knowledge of the other firm to get efficiency in the short term through systematic improvement and refinement because what impels low risk, variance, and predictability of returns. For exploration, high variance and unpredictable returns are acceptable since the objective is to discover new opportunities and to achieve effectiveness in the long term through discontinuous innovation. Transaction cost research suggests that the higher the uncertainty, the more likely it is that firms will seek to control activities through vertical integration rather than through some form of SC relationship (Tokman et al., 2007).

\subsubsection{Business performance}

Kristal et al. (2010) hypothesise that ambidextrous SC strategy has a direct and positive influence on combinative competitive capabilities, which in turn, improve business performance, namely, market share and profit level. Combinative competitive capabilities reflect an organisation's ability to achieve low cost, high flexibility, dependability, and quality. A company should seek to achieve economies of knowledge in its SC (Roth, 1996) by which operational capabilities are enhanced dynamically.

\subsection{Supply chain archetypes}

An SC archetype is a design pattern of the SC, which defines the key factors of the business framework, the relevant attributes of the unique value chain, and how to perform the design factors of the SC processes, ensuring the alignment of the SC with the 
organisation's competitive strategy. Perez determined six SC archetypes (Perez, 2013) (see Table 1), which are grouped in two categories

1 those driven by efficiency which is a usual behaviour in low-cost fashion industry

2 those driven by responsiveness showing relevance for agile response to demand variation, high product adaptability, and a broad portfolio of products to reduce costs of market uncertainty.

Archetypes will be used as role models to fill gaps in a company's SC strategy.

The intermediate zone between the six archetypes has been ambiguously described by researchers because there is no affinity in their proposed concepts (Harris, 2007). Apparel brands operate mostly between two archetypes Fast and flexible; however, SCs in this industry also reveal some of the characteristics of the efficient and agile archetype; these four archetypes are described with more detail below. The Continuous Flow and Custom Configured archetypes will not be analysed since they are not suitable for this industry.

Table $1 \quad$ SC archetypes

\begin{tabular}{lccc}
\hline Driver & \multicolumn{3}{c}{ Archetypes } \\
\hline Efficiency & Efficient & Fast & Continuous flow \\
Responsiveness & Custom configured & Flexible & Agile \\
\hline
\end{tabular}

Source: Adapted from Perez (2013)

\subsubsection{Fast archetype}

The fast archetype is characterised by a continuous and quick renewal of products framed in an efficient operation because they are often changing due to fashion or technology or a combination of both. These SCs have a high market uncertainty cost. The most relevant value attribute is the time from idea to market. Some characteristics are:

- Prices should be at least in the average of the industry or lower. Products are oriented to seasonal trends with a very short period of life, so it is demanding perfect orders. The main driver is the reduction of market-mediation costs.

- Managerial focus with three capabilities, a short time from idea to market, the maximum level of forecast accuracy to reduce market-uncertainty costs, and end-to-end efficiency to ensure affordable prices.

- Factors to succeed: Basic SKUs should be fastly replenished, state-of-the-art forecasting techniques, develop the ability to produce small batches, products spend little time in the distribution centres (DCs).

\subsubsection{Efficient archetype}

When the focus is on efficiency, these SC usually increase the capacity and specialise in a few products or services, oriented to the lowest total cost. That means basic/stable, but easy substitutable products with no significant changes where the customer has the power. The decision of the customer is the price then is well suited for business with commoditised products in an industry with high scale assets, oriented toward low costs. Considerations when implementing this archetype are (Perez, 2013): 
- Supplier management should be an opportunistic approach to take advantage of the best cost at each moment.

- Inventory strategy is to keep inventory levels to secure power over suppliers.

- Production should be planned based on sales expectations.

- Demand fulfilment is characterised by enough finished inventory, minimum order quantity, and order cycle defined by lead-time.

- Managerial focus on two actions to maximise end-to-end efficiency:

- $\quad$ ensure complete asset use and overall equipment efficiency

- $\quad$ ensure forecast accuracy to guarantee product availability and perfect order fulfilment.

The factors to succeed are extra capacity in outbound logistics to absorb demands peaks; to reduce productions and service production, eliminate high-variation and low-demand SKUs; minim order-size policy; when market demand evidences seasonal trends, extra warehousing capacity should be available.

The main distinctions between the fast and the efficient archetypes are the market uncertainty costs and demand variations, which are higher on the fast archetype because the industry is highly affected by changes in consumer preferences, so companies require to shorten developing times and to ensure continuous renewal of product portfolio. The efficient archetype has a lower market uncertainty cost, which eliminates the need for renewal of the product portfolio, but the price becomes the major attribute.

\subsubsection{Agile archetype}

This archetype appeals for agility, so the SC quickly responds to the demand of a very rapid and personalised product or service, since these aspects determine the buying decision. The cost of market uncertainty is very high, and high variability in lead times required by the customer, often below the industry. As a result, the central aspect of competing is agility, the ability to meet unpredictable demand under unique specifications, in quantities exceeding the forecast, within a shorter lead-time than agreed (Perez, 2013).

The ability to be agile is proportional to the ratio between excess capacity and the average rate of asset usage. In strict terms, there can be no agility without excess capacity. Some considerations when implementing this archetype (Perez, 2013):

- $\quad$ The supplier's management is to be approached collaboratively to ensure agile sourcing.

- Inventory strategy is to keep enough number of components; thus, a product portfolio with a common platform of components would be beneficial.

- Due to fickle production cycles, a strategy is to reduce changeover times among SKUs.

- Demand fulfilment is characterised by excess capacity and minimum production batch. 
- Managerial focus by having these three capabilities: (i) enough excess capacity, products, and processes (ii) designed to produce the smallest possible batches, (iii) and fast transactional processes that set short lead-time.

Factors to succeed are a common component platform (products built with the same components). These components should always be available

- low-variance customers should be protected by lower prices

- if extra capacity gradually decreases, the company should invest in additional assets in order to maintain its agility.

\subsubsection{Flexible archetype}

This archetype refers to unique solutions, products, and/or services that meet unique customer needs. Lead times demanded by customers are very short, often a matter of urgency. The purchase decision is triggered by quickly obtaining unique solutions; consequently, the price is no longer a relevant attribute. Considerations when implementing this archetype (Perez, 2013):

- Supplier's management should have a pool of strong collaborative relationships with suppliers that share their permanently available-to-promise at any moment.

- Inventory strategy is focused on maintaining a low level of inventory of components and pooling of components shared with competitors and customers. Moreover, the inventory is in parts, components, or semi-finished products located before being processed in the finishing process.

- Product and transformation processes are adapted to each customer order.

- Demand fulfilment is characterised by understanding and satisfying customer needs.

- Managerial focus considers five capabilities, standby capacity of critical resources; many low-throughput assets; technical strengths; the quick response from order entry to design; and process flow that is designed to be quickly reconfigurable.

The main factors to succeed comprise:

- companies should keep critical resources, including those of competitors, because these companies are oriented to addressing unexpected situations

- $\quad$ strong collaborative relationship with key suppliers

- a well-designed order-entry process.

The main differences between agile and flexible archetypes are in the demand pattern, and the degree of product adaptability since the combination of both high demand variation and high-product renewal rate implies the highest level of market uncertainty cost.

The revised subject of the ambidextrous SC effectively includes the concept of simultaneity, that is, to achieve two objectives that are not necessarily in the same direction. Nevertheless, innovation is not strictly expressed in the previous definitions. 
However, most innovation definitions have the intrinsic objective of maintaining competitive the organisation. It is worth noting that some of the ASC definitions presented do not provide a holistic concept but address particular points of view on how the networked breakthrough innovation happens. For example, Kauppila (2007) affirms that companies make each other ambidextrous in a network by supplementing each other's and outside knowledge and other resources.

\section{Study methodology}

The steps that constitute the methodology are described next:

1 The theoretical framework was developed after reviewing relevant literature from the fashion industry and apparel SC, ambidexterity/ ambidextrous SC (ASC), and SC archetypes. The review shed light on how these areas, when taken together, also allowed a broad spectrum of research in which little had been done. There were very few attempts on the definition of a general concept for ASC, yet concrete ways of how to perceive ambidexterity in an SC were described.

2 Research objectives were developed, which were divided into two parts:

i Definition construction with all the information gathered in the theoretical framework, and then a proposed definition was made to flesh out what an ambidextrous SC in the apparel industry is.

ii Data collection and lists of best practices using Gartner SC Rankings. Three companies had been escalating positions year after year: Inditex, H\&M, and Nike; case studies focused on SC management were collected: 12 from Inditex, eight from H\&M, and seven from Nike. After analysing companies' cases, a list of best practices was created. Each best practice was catalogued in exploitation, exploration, or ambidextrous practice. With this list, the proposed definition would be approved or not.

3 The balance of SC archetypes, after reviewing the theory, and generating the list of good practices, it was concluded which SC archetypes were balancing each of the leading firms. An "assessment for ambidexterity in the apparel supply chain" (AAASC) tool was developed and used. At first, it was determined that the three met with many of the features of the Fast archetype. Thus, each firm balanced this archetype with one or more archetypes. More details of the AAASC tool are in Section 4.3, and Appendix 1. Two SC experts validated the practices in the AAASC tool for each of the three cases according to evidence.

4 Conclusions were analysed about the proposed ASC definition, according to the best practices, on how it precisely defines how would be the ambidextrous SC approach for the leaders in the industry; limitations of the study were identified, and the contributions of the research were set.

In Figure 1, we present the research methodology. 
Figure 1 Research methodology

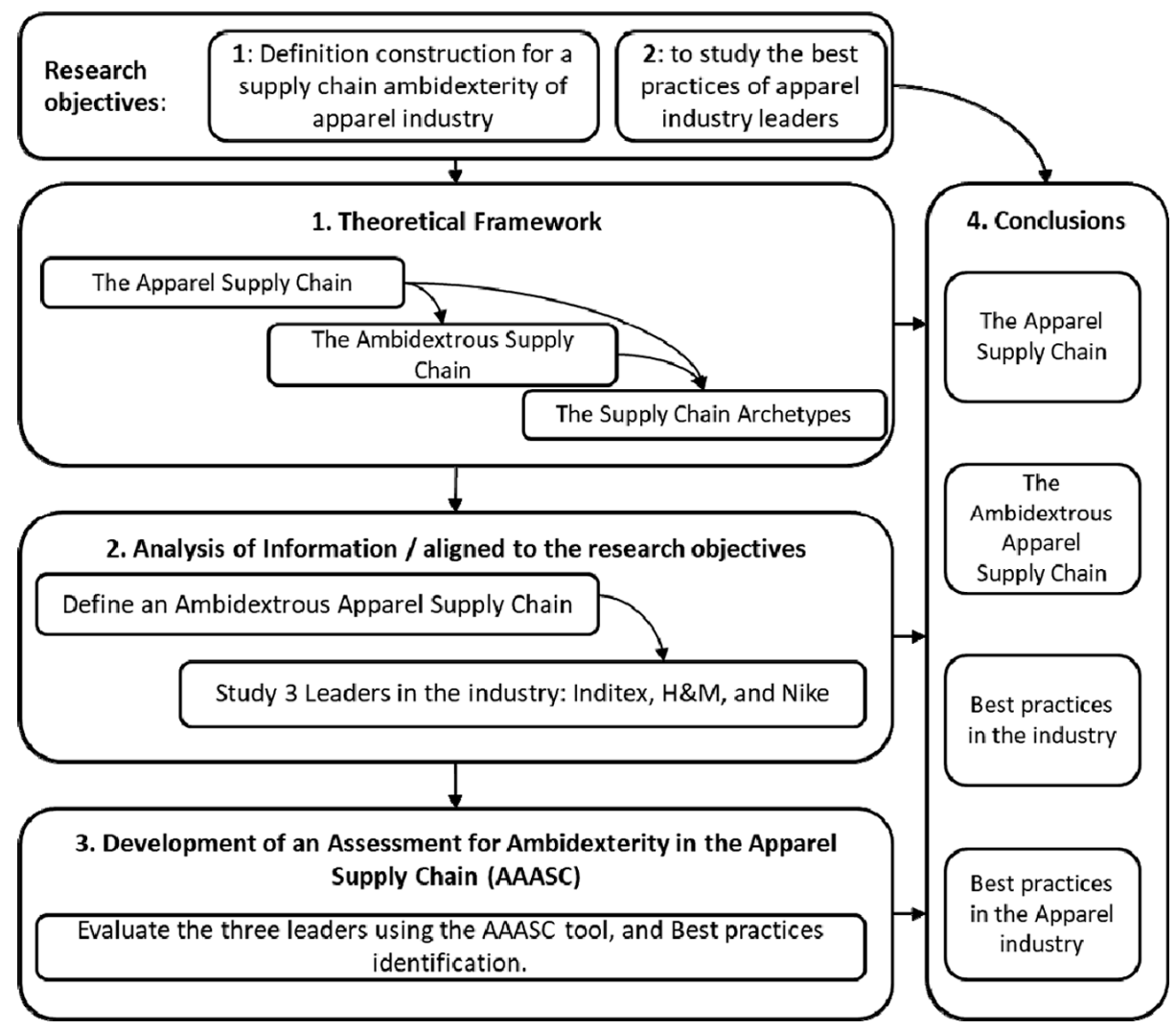

\section{Discussion of results}

In this section, the principal results of the study are listed, first the proposed definition for ASC, then the analysis of the three cases of study, and finally, the validation of the proposed definition with the cases of study.

\subsection{Proposed definition for ambidextrous supply chain}

A review of the literature was performed. A generally accepted definition of an ASC lacks in the literature. The term embodies a multitude of concepts that are related to different aspects of the SCM, so it gets hard to build a general definition that may apply to any SC in any industry. Even with the complications mentioned in the previous paragraph, one of the objectives of this research is to construct a definition of ASC that can fit with the characteristics of SCs in the apparel and fashion industry. The following definition is the most precise produced so far for retail industries. The last three lines highlight capabilities when strictly speaking, for the apparel industry to customer fulfilment: 


\begin{abstract}
"An ambidextrous supply chain is one in which the resources of all network participants are exploited. Simultaneously, these resources are put to work to achieve the breakthrough innovations that will bring improvement in productivity and benefit not only to the focal firm but for all the network members. This means that the exploitation and exploration are conducted both internally for each company in the chain, but also between companies.

Specifically, in the apparel industry, an ambidextrous supply chain highlights three capabilities: simultaneity for customer satisfaction, skill in handling tradeoffs, and a balance of archetypes for supply chain strategy."
\end{abstract}

For this definition, some terms will be clarified:

- Exploitation: is associated with concrete decisions on production and efficiency, selection, implementation, and execution. In a fast-changing dynamic context, such as fashion's it is demanding to exploit the demand side.

- Exploration: is associated with discovering, playing, taking risks, diversify, be flexible, experiment. In a fast-changing dynamic context, such as fashion firms ought to search for innovation and explore the supply side and geographic space.

- Resources of all network participants: it is that all parties understand that the current environment of the innovation is networked, that is, to involve a diverse body of collaborators in innovation processes. Especially for the apparel industry is essential to balance three specific features:

i the relationships approach with partners way up/down, left/right in the SC (relational or contractual)

ii the flow of information, knowledge and internal and external learning

iii the repeated close collaboration and variety of suppliers; all this to ensure speed and flexibility always.

- Simultaneity: that is, to achieve two objectives that are not necessarily in the same direction.

- Handling tradeoffs: the most common tradeoffs in the industry is the choice among savings and lower costs, better quality, more variety, shocking marketing, responsiveness, and flexibility to assimilate the latest trends.

- Balancing archetypes for SC strategy: balance of the pair formed by one of the archetypes driven by responsiveness (agile or flexible) and one of the archetypes driven by efficiency (fast or efficient).

Through the identification of good practices from the industry leaders, it is intended to corroborate that most practices match mostly with the described previously; so, it can be inferred that SCs in the apparel industry lean towards to ambidexterity.

\title{
4.2 Fashion retailers in the ranking
}

Gartner Top 25 SC reports were reviewed from 2011 to the latest delivery of 2018, and both Inditex and Nike appear since then. On its side, H\&M was firstly considered in the ranking until a year later, 2012; nonetheless, H\&M has quickly reached its competitors with a dramatic rise in its position in the ranking, and by 2018, the three brands are 
within the top 10 (Aronow et al., 2018). This is mainly because out of the three brands, $\mathrm{H} \& \mathrm{M}$ is the one with the highest and most sustainable return on assets (ROA) over the years.

\subsubsection{Case 1: Inditex}

Inditex (abbreviation for its name in Spanish, Industria de Diseño Textil S.A.), was born in 1985 when the current owner, Amancio Ortega, joined a computer expert José Maria Castellano to design a highly responsive SC that could quickly produce latest fashions. A group of designers replicates popular items, nearby factories produce them, and they are shipped from a central warehouse to the stores. Sophisticated proprietary information systems allow designers, factories, warehouses, and stores to communicate with each other rapidly and avoid fashion misses (Wells and Danskin, 2013).

Inditex is one of the largest fashion retail groups in the world, with nine brands and over 7422 stores in 96 countries. The Group's brands strive to sell fashionable products of the highest quality. A state-of-the-art logistics system centred in Spain helps deliver new products to all of the Group's stores twice weekly to meet their customers' needs (Inditex, 2018).

There are many examples of success apparel brands that create value through the FSC (Zhang, 2008a) despite the short life cycle of the product to commercialise (fashion). Inditex is a constant in the literature reviewed and maybe the best example of this success through SCM because it has grown up into the world's first-class fashion retail group with a high competition within such a short time (Zhang, 2008b). It owes its achievement to many reasons, but one of the most important is its efficient SC system that significantly reduces the lead time (the time from designing to the selling of garments to the consumers). The time is usually 6-9 months for Chinese clothing industry, four months for the international brand, and only 7-12 days for Inditex (Zhang, 2008a).

The efficiency of Inditex originates from the small scale in operations, which includes order reception for the small lot in high frequency, small batch production and transportation, and distribution in small quantity, that is, seeking fast from small (Zhang, 2008a). When most apparel companies outsource production in low-cost countries in Asia, Inditex manufactures approximately half of its merchandise in its network of more than 22 Spanish factories, with just-in-time systems (Man, 2009). Production lot should be kept as small as possible, leaving out extra capacity in the products which are most needed in the manufacturing market (Zhang, 2008a).

In the case of Inditex, the chain coexists with the brands. Without the support of a brand, that chain may be impossible. So, no brand image will be built without such SC. The whole process of the SCs in Inditex could be divided into four parts: product organisation and design, purchase and production, product distribution, sales, and feedback, which are all client-focused and brand-guided (Zhang, 2008a).

Inditex model has become a kind of ideal view of agile SC for the fashion industry. It strongly emphasises the philosophy of market-driven SC and demand chain management, which considers that volatile consumer-demand pulls the entire SC (Dari and Paché, 2013). These models also consider that the performance of competitive SCs is related to a high velocity at an acceptable logistical cost (Byoungho et al., 2012). If the product is unsalable, the original production plan will be cancelled. Only $15 \%$ of the estimated sales are put into production at the current season, so the risk is controlled to a minimal (Zhang, 2008a) Inditex SC is shown in Figure 2. 
Figure 2 Inditex supply chain

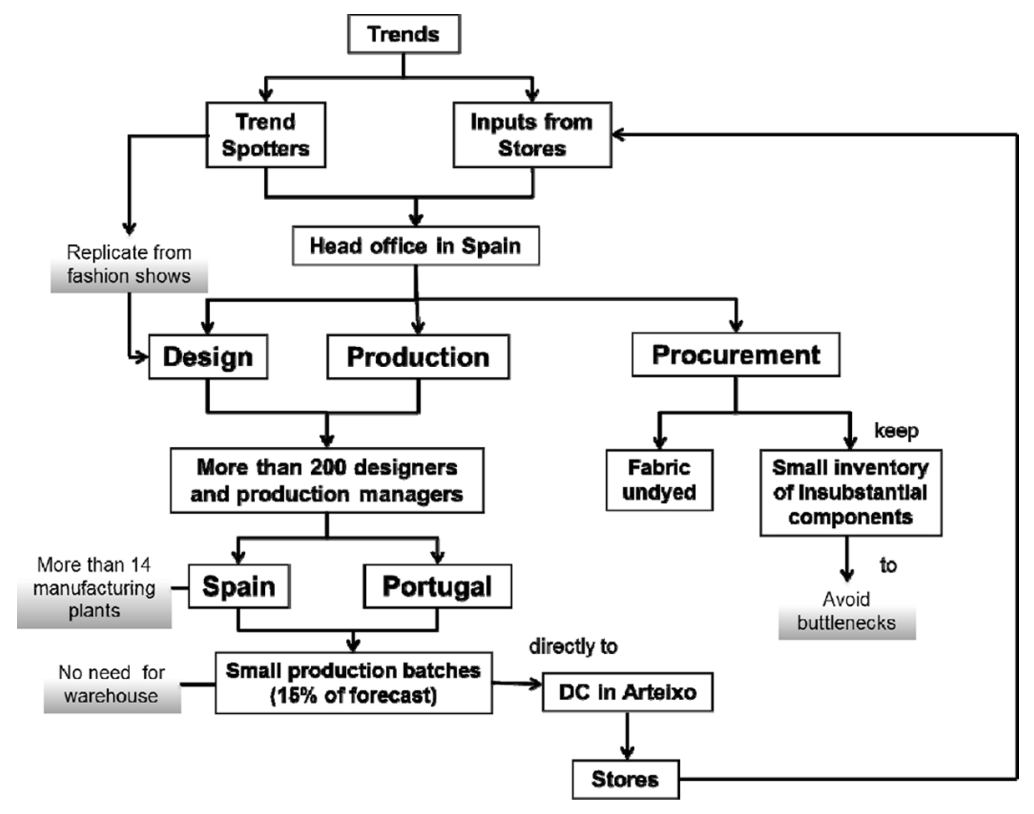

\section{Supply chain best practices}

A nonstop flow of information from stores conveying shopper desires and demands inspiring the team. Leverages social networks and product scarcity to sense and shape demand. It has a multiple brand portfolio for a market segmentation strategy and to respond to the different targets demand. Inditex manages its demand by only manufacturing the $15 \%$ of the forecasted production, so the losses incurred for clothes out of favour can be disposed of with minimum losses.

Inditex's SC does not minimise costs (e.g., shipments by plane) but worked towards maximising revenues. Inditex signed an accord with H\&M to improve factory safety conditions. Conscious trade-off decisions, for example, spend little on advertising to spend more on local production to deliver speed-to-market. The company balances between its expansion and the vertical integration: the farther it moved its operations from Spain, further away from the DC and higher distribution costs.

Furthermore, Inditex is characterised by rapid prototyping and time-to-market for new products. Fabrics and other raw materials are bought in advance in quantities that allow leveraged spending, instead of fashion trends, Inditex concentrates its forecasting efforts on the kind and amount of fabric to buy since fabric mistakes are cheaper than finished clothing mistakes. A small inventory of inexpensive, non-bulky components is kept since they are often the cause of bottlenecks such as buttons or zippers to finish clothes even if SC breaks down.

Inditex is characterised for highly integrated SC but the segmented approach to maximise fulfilment for seasonal products and reliability for basic and core products. SC controls through ownership, and in-house execution remains a cornerstone of Inditex's strategy. Functions such as sourcing, design, manufacturing, logistics, and distribution are critical features of this company's vertically integrated SC operations and are crucial to the retailer's excellent flexibility and speed. Active supplier collaboration 
accomplished by looking for opportunities for continuous improvement while keeping compliance with the Code of Conduct for Manufacturers and Suppliers. Each supplier in the Inditex SC is subject to periodic and surprise audits; the aim is to verify their compliance.

By having fresh stock twice a week, Inditex guarantees continuous customer inflow to its stores. It also works with a system to manage complains with highly integrated SC but the segmented approach to maximise fulfilment for seasonal products and reliability for basic and core products. The Inditex Group has launched initiatives such as an item locator service.

\subsubsection{Case 2: $H \& M$}

H\&M is both an importer and retailer. In 1947 Hennes women's clothing store opened in Västerås, Sweden. Today the H\&M Group offers fashion for everyone under the brands of H\&M, COS, Monki, Weekday, Cheap Monday, and \& Other Stories, as well as fashion for the home at H\&M Home. H\&M has expanded substantially in recent years, with 4,500 stores are spread across 62 markets worldwide. The brand has risen dramatically in the Gartner SC Top 25 thanks to his outstanding ROA (Aronow et al., 2018).

Its value proposition is that they should always offer inspiring fashion with unbeatable monetary worth. H\&M ensures the best price by having cost-consciousness in all parts of the organisation; by an in-house design and efficient logistics without intermediaries, as well as by buying the right products from the right markets (H\&M, 2017).

$\mathrm{H} \& \mathrm{M}$ does not own factories but instead buys products from independent suppliers that are closed long-term. The group has a sustainable philosophy built on seven commitments: provide fashion for conscious customers; choose and reward responsible partners; be ethical; be climate-smart; reduce, reuse, recycle; use natural resources responsibly and strengthen communities. H\&M's design department employs 160 in-house designers and 100 pattern makers, as well as several design assistants and print designers. Working from their Head Office in Stockholm, they create H\&M's wide-ranging and varied collections. The team is vast and diverse, representing different age groups and nationalities. The brand states that its design process is about striking the right balance between fashion, quality, and the best price. Moreover, it always involves sustainability awareness, which means a strong consideration for both people and the environment, all the way from the sketchbook to the customer (H\&M, 2017).

H\&M's flexible assortment planning ensures that each store's selection remains updated, on-trend, and relevant to its customers. Different factors determine the final composition of merchandise. Results for past seasons are combined with analysis of up-coming trends, colours, and fits. Demographics and geography also influence the distribution of products: high-fashion garments produced in limited quantities are sold mainly in big cities while basics are ordered in larger volumes and widely distributed (H\&M, 2017).

The H\&M production offices are located in the same sourcing markets and are the primary contact point for the local suppliers, handling timing and practical aspects of all orders. They have a team of 80 people who audit working conditions at supplier factories against H\&M's code of conduct. They also perform extensive safety, quality testing to ensure that chemical requirements are met. Lead times vary from a few weeks to six 
months, with high-volume products such as basics and children's wear ordered far in advance, while more trend-led garments in small quantities can be produced at shorter notice.

The more significant part of shipments from the suppliers' factories goes directly to logistic centres in H\&M markets, which support stores in their geographic vicinity. Further, stores do not have back up stocks but are replenished as required from the DCs. One H\&M's challenge is to fulfil customer requirements and keep the rapid pace of the group's growth while making sure its transportation has the least possible impact on the environment. Therefore, they strive to avoid air and road transports whenever possible, work with environmentally friendly transport companies, and have more efficient logistics. In 2012, around $90 \%$ of the brand's goods were transported from suppliers to the DCs via sea or rail.

H\&M's growth target is to increase the number of stores by $10 \%$ to $15 \%$ per year, and at the same time, increase sales in comparable units. The steady pace of expansion continues into 2015 with a planned 400 new stores. Stores are run by H\&M, except for some markets like China, where they collaborate with franchising partners (H\&M, 2017). H\&M SC is shown in Figure 3.

Figure 3 H\&M supply chain

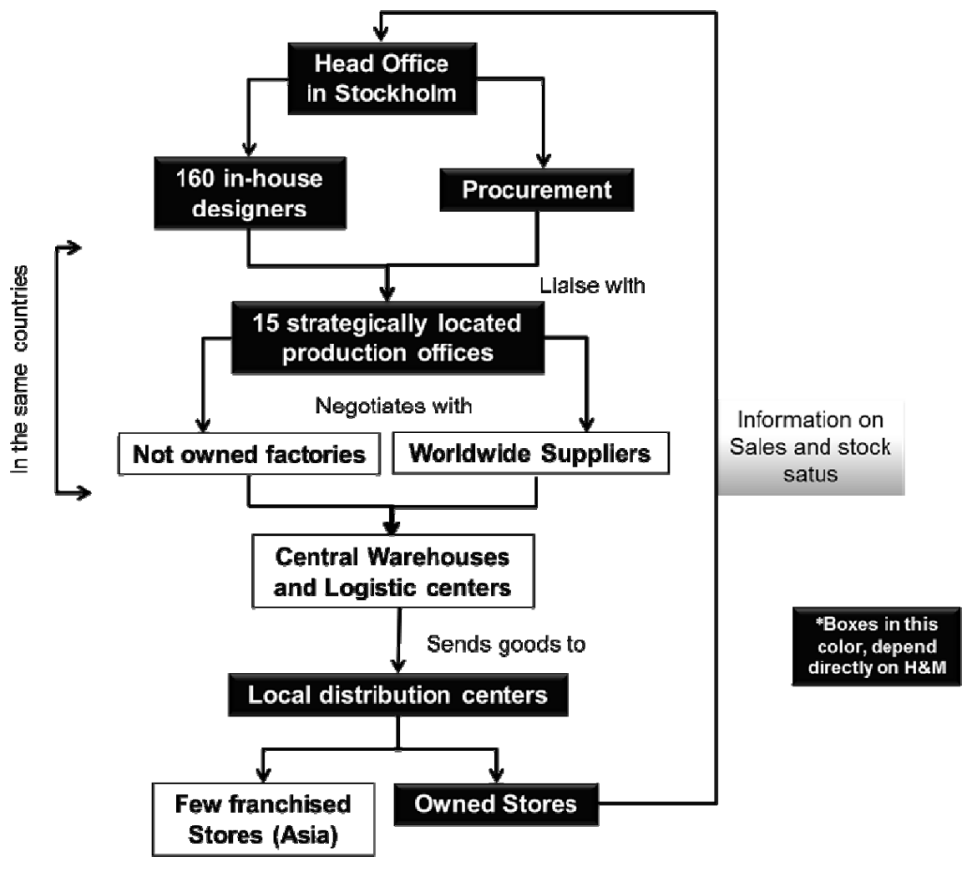

\section{Supply chain best practices}

When goods are selling well, H\&M can get supplementary orders out into the stores within just a few weeks (negotiations with suppliers). H\&M also adapted its product portfolio depending on the store location; for example, stores in big cities often sold more garments with high fashion content than stores in suburban shopping malls. Daily communication, both formal and informal, is maintained between the head office and all the stores to know the customer demands genuinely. In 2004, H\&M acquired all the 
10 GAP stores in Germany, including the employees, with the attempt to acquire their demand as well.

H\&M organisation balances between reasonable price, time and quality; H\&M's strategy focuses in aggressively expanding while driving costs down, it practices economies of scale through enormous quantities ordered, cost controls mainly in the administrative levels, and effective costs and logistics: one quarter of the stock was made up of fast-fashion items designed in-house and farmed out to independent factories. On the other hand, the H\&M organisation has the goal to be at the forefront of sustainability, so it signed an agreement with Inditex to improve factory safety conditions.

H\&M has a remarkable product lifecycle management maturity by committing to eliminate pulp from forests from all their rayon/viscose clothing. Partnership with the world wildlife fund (WWF) to develop a global water strategy across its extended SC. Economies of scale through enormous quantities ordered, cost controls mainly in the administrative levels, and effective costs and logistics: one-quarter of the stock was made up of fast-fashion items designed in-house and farmed out to independent factories.

Also, H\&M has a proprietary distribution network of centrally controlled stores. It manages and commissions its suppliers through a network of 15 strategically located global buying and production offices. Each of these locations has its SC design. H\&M does not have any factories of its own, but 700 suppliers in Asia and Europe and 22 production offices, around the continents. Its operation is through two SCs to optimise time and cost. H\&M accomplishes transparency in its supplier relationships by publishing a supplier factory list in its reports joint to effectively manage the relationships between 160 in-house designers and 900 independent suppliers.

On the other hand, H\&M has balanced the centralised and decentralised SC operation processes. The centralised vital activities correspond to those such as design, merchandise planning, trend forecasting, and purchasing while fully outsources production. Sophisticated IT for replenishment, because stores introduce new lines daily and no line remains in a store for more than one month.

Likewise, H\&M manages an aggressive growth path, with plans to open 240 stores worldwide in 2018. Tough and short lead times for a quick response to market trends. H\&M balances customer value while driving costs down: to pass the savings to the costumers (cost consciousness, low price reductions, cost-efficient expansion, and positive effects from a weaker dollar) rather than increase margin and profit.

\subsubsection{Case 3: Nike}

Founded in 1957 by Philip Knight, Nike manufactures high-quality athletic shoes for a variety of sports, including baseball, athletics, golf, tennis, volleyball, and wrestling. In addition to footwear, Nike also manufactures fitness equipment, apparel, and accessory products. The company's products are sold in over 140 countries around the world (Chaturvedi and Gupta, 2005). Wholly owned NIKE subsidiaries include Converse Inc., Cole Haan, Umbro Ltd., and Hurley International LLC (Nike, 2012). Its formula has been: "Being good at innovation and productions while being able to sign great athletes" (Uyterhoeven, 1993).

As mention before, innovation is a cornerstone of the Nike brand. This broader vision calls for new approaches to design, management, partnership, and new tools and metrics to support integration and adoption throughout Nike. Due to its position at the beginning of the SC, the design function offered an excellent opportunity to design with 
breakthrough innovations and out environmental issues (Vogel and Ramallo Garcia, 2012).

All product development factory, contracting, and marketing activities are carried out at the company's headquarters in Beaverton, Oregon in the US. Nike's global operations are broadly divided into geographic regions: the USA; Europe, the Middle East, and Africa; Asia Pacific, and the Americas. Since the mid-1970s, Nike has outsourced its manufacturing activities. Products are manufactured in factories owned and operated by its business partners, commonly known as contractors around the globe (Chaturvedi and Gupta, 2005).

Back in the years, to Nike, getting a new athletic shoe model on a store shelf could take 15-18 months from initial planning to final product distribution. Volumes were determined long before shoes arrived at consumer outlets, requiring accurate forecasting from NIKE and its merchants. A typical new Nike shoe had a market life of 3-6 months from introduction to depletion of inventories (Nike, 2015).

Nowadays, Nike's retailers placed orders six months before the required delivery date with the guarantee that $90 \%$ of their orders would be delivered within a set period at a fixed price (Chaturvedi and Gupta, 2005). Nike has the policy to evaluate potential contracted factories before they enter the SC to assess compliance with standards including country-related risk for issues, forced labour, human trafficking, and slavery. Nike uses both internal and external third-party audits. Nike is working on mapping and understanding impacts further up the SC, to develop standards for upstream suppliers of contracted manufacturers (Nike, 2015).

Nike began to carefully analyse their operations in the early 1990 s, after facing a storm of criticism over its labour practices in its Asian suppliers. It was then asked about the long-term implications of their production decisions and product design. They found that it was possible to produce three garments with the material that was used for two. As a result, a zero-waste policy was created in collaboration with other partners such as Dow Chemical, DuPont and BASF, because Nike knew that it could not achieve its objectives without improving the SC (Fromartz, 2010).

By 2004, the company had successfully implemented its Nike Supply Chain (NSC) project, indicating that the centralised planning, production, and delivery processes were right for the single instance strategy. With this success, Nike's Single Instance Strategy became the desired approach for many companies implementing ERP software (Chaturvedi and Gupta, 2005). Nike uses SAP for 95\% of its global business. The remarkably particular NSC, where there are more players on each node, can exploit the knowledge and learning from them so that together, they could share and explore product innovation. Nike SC is shown in Figure 4.

\section{Supply chain best practices}

Responding to trends and shifts in consumer preferences by adjusting the mix of existing product offerings, developing new products, styles, and categories, and influencing sports and fitness preferences through extensive marketing. Improved supply flexibility to address the uncertain outcomes of sporting events.

The SC leadership team at Nike is well-balanced between new and veteran players. In Nike, it was developed the 'allocation method' strategy: targeting the important markets (such as Los Angeles, Chicago, New York) and the large specialty distributors 
such as 'Foot Locker'. Nike's formula has been: "Being good at innovation and productions while being able to sign great athletes" (Uyterhoeven, 1993).

Figure 4 Nike supply chain (see online version for colours)
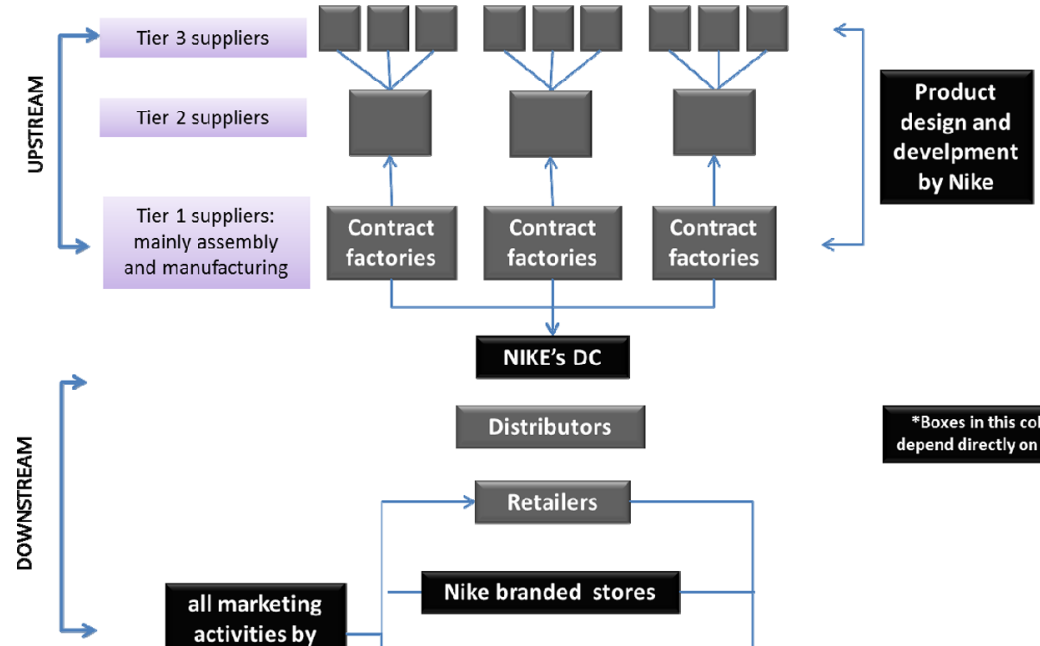

NIKE'S DC

Distributors

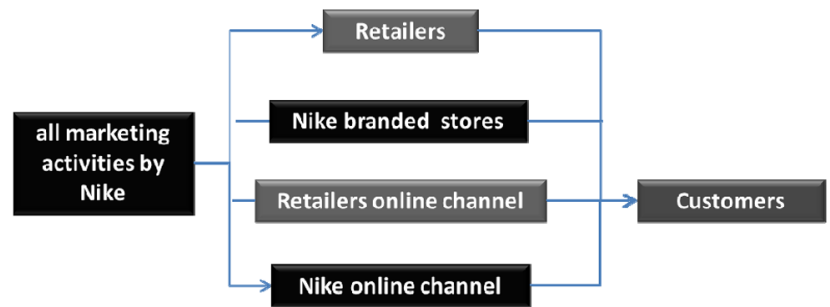

Another best practice is the segmented SC capabilities and advanced analytics for SC design. Thanks to the NSC, Nike now creates a build-to-order SC where they buy from partner factories based on actual customer demand rather than forecast (efficiency and pull).

Supplier assessment tools that incorporate sustainability-related metrics and use of advanced scenario analysis is another best practice. Nike uses both internal and external third-party audits. Nike combined monitoring with collaborative activities with suppliers that were designed to improve working conditions and develop systems to improve production planning and reduce overtime.

The brand operations are managed within a geographic segment: North America, Western Europe, Central \& Eastern Europe, Greater China, Japan, and Emerging Markets. Nike's independent contractors and suppliers buy raw materials in bulk for the manufacturing of our footwear, apparel, and equipment products. Most raw materials are available and purchased by those independent contractors and suppliers in the countries where manufacturing takes place. Nike increased precision across its supply network by investing in collaborative platforms and tools for its suppliers, logistics providers, and contract manufacturers.

Moreover, Nike expands its product portfolio very often. Because of greater information and better communication with collaboration with its partner factories, Nike can shorten its lead times for footwear from 9 to 6 months. It responds to trends and shifts in consumer preferences by adjusting the mix of existing product offerings, developing new products, styles, categories, and influencing sports preferences through extensive marketing. 


\subsection{AAASC tool}

It is a hybrid tool that provides some appraisal for the ambidexterity capability, not only for a company or brand in the fashion industry but throughout the whole SC. It accumulates scores and generates graphics that bring out an idea about the tendency for ambidextrous practices in any ASC.

The tool is divided into seven sections:

1 demand management

2 strategy and organisation

3 product life cycle

4 supply chain design

5 supply chain governance

6 supply chain operations

7 customer fulfilment.

Each section contains a matrix in which the rows are different characteristics or features for that specific dimension and three columns (exploitation, exploration, and ambidextrous). The characteristics features (rows) derive from synthesising the entire database generated with the best practices of the $3 \mathrm{SC}$ leaders. At each intersection, there is an explanation that defines how is the feature for that stage, either exploration, exploitation, or ambidextrous. The user assigned a number depending on how many practices are taken into the $\mathrm{SC}$ for each of the intersections. Appendix 1 shows one section of the AAASC tool.

The AAASC can be appreciated in the Venn diagram of Figure 5 since it was framed by mixing three aspects or matters of discussion:

- $\quad$ SCM and ASC theory and assumptions

- SC leaders' best practices

- the seven dimensions of the DDVN Gartner's model.

The tool aims to create a visual output in which three ideas are integrated (SCM/ASC theory, SC leaders' best practices and the seven dimensions of the DDVN Gartner's model) and help to appreciate the predisposition by any SC in the apparel industry into the ambidextrous practices in different SC dimensions. With the latter is confirmed that the tool undertakes any SC of any brand in the industry to be appraised.

\subsection{Validation of the proposed ASC definition}

A contrast between the three leaders' best practices and the elements composing the proposed definition for ASC is presented to validate if this definition works for the apparel industry.

Exploitation: it is the most obvious in trying to verify the proposed definition as each of the three brands is trying to maximise their resources. 
Figure 5 Related aspects of the hybrid AAASC tool (see online version for colours)

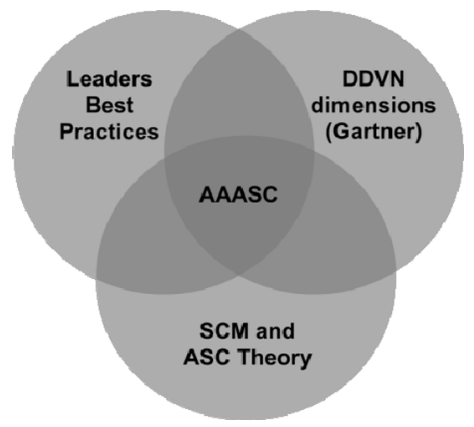

Exploration: Nike explores supply-side and geography because it has many different channels to get the final consumer. Both Inditex and H\&M have diversified themselves with the operation and exploitation of different brands to different markets. They also innovated by diversifying not only in apparel but in home-accessories. Inditex has one of the riskiest but innovative SC practice: it has several kilometres of railroad linking its factories, and its distribution centres. H\&M has been risky when experimenting with expensive and limited-edition collections designed by famous designers.

Resources of all network participants: These brands exploit not only their resources but manage contractual and relational relationships with partners to exploit the rest of resources throughout the network. Inditex is the only one that avoids this negotiation by owning much of its vertically integrated SC. On its side, Nike exploits various resources of its partners by repeated collaboration with them so that it can have formed in advance certain raw materials to the very specialised expertise in ICT's of some partners.

Simultaneity: In this industry, players in the SC can serve its current customers on different channels with one warehouse, while exploring new innovative channels to meet new customer segments. This distribution channel complexity requires prudent management of its warehouses and distribution centres. Simultaneously these three SC industry leaders manage to maintain productivity metrics inventories.

Handling tradeoffs: The most common tradeoffs in the industry is the choice between saving and lower costs, better quality, more variety, shocking marketing, faster speed and responsiveness and flexibility to assimilate the latest trends. For example, Inditex spends little on advertising, to spend more on local production to deliver speed-to-market. Balancing archetypes for SC strategy: The three of them include the Fast Archetype in this balance since this archetype is always evolving due to the fast-changing rhythm of fashion and technology.

Fast archetype: Referring to the critical points of this archetype, the three manage a collaborative approach with their suppliers, mainly to buy in advance and have the best price. In terms of ambidexterity, they explore different suppliers to anticipate trends but operate at a fixed pool of suppliers for disruptive risk management. Inditex is the one that has less contact with suppliers, only for some raw materials, because it owns almost the whole chain. The three are modelled on single batch production per SKU, and besides, Inditex has three parallel production lines for each target: woman, man, kids. Inditex, $\mathrm{H} \& \mathrm{M}$, and Nike have a collection approach for demand management. 
To the fashion rhythm, end-to-end efficiency is highly important to ensure affordable prices. Inditex and H\&M prices are competitive among them. Nike is priced above its competition, so this aspect is not part of its value proposition; therefore, its chain is not as integrated to be precisely the most efficient. It has many players and intermediaries. One of the success factors for this archetype is the ability to produce small batches. Inditex achieves this with only $15 \%$ of the forecast production to verify whether it will work or not (decrease risk).

The balance of the fast archetype with the other archetypes in each of the three companies is explained next.

Inditex: It balances the fast, the flexible, but also the agile efficient archetype (see Figure 6). In the Agile archetype, SC responds quickly to the changes in demand. It is the ability to meet unique specifications under unpredictable demand in quantities exceeding the forecast within shorter lead-time than agreed. Inditex accomplishes such features through $15 \%$ of forecasted production, undyed fabrics, and state-of-the-art manufacturing machines. Demand fulfilment for this archetype is characterised by excess capacity and minimum production batch, and Inditex does precisely that. The fast-transactional processes that set short lead-times are achieved with the vertical and owned Inditex SC, in which non-bulky components that cause bottlenecks are always available.

Figure 6 Balance of SC archetypes for Inditex (see online version for colours)

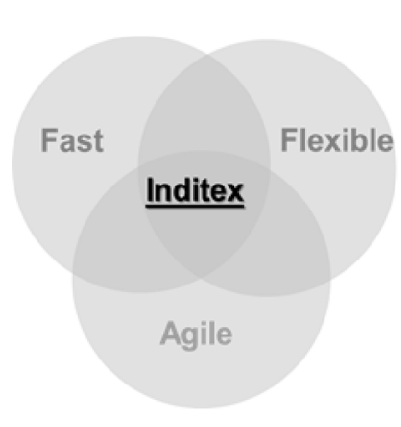

\begin{tabular}{|c|c|c|c|}
\hline DIMENSION & EXPLOIT & EXPLORE & AMEIDEXTROUS \\
\hline $\begin{array}{c}\text { Demand } \\
\text { Management }\end{array}$ & 3 & 4 & 4 \\
\hline $\begin{array}{c}\text { Strategy and } \\
\text { Oranization }\end{array}$ & 4 & 8 & 4 \\
\hline $\begin{array}{c}\text { Product Life Cycle } \\
\text { Management }\end{array}$ & 3 & 3 & 1 \\
\hline $\begin{array}{c}\text { Supply Chain } \\
\text { Design }\end{array}$ & 2 & 5 & 5 \\
\hline $\begin{array}{c}\text { Supply Cllain } \\
\text { Governance }\end{array}$ & 5 & 7 & 5 \\
\hline $\begin{array}{c}\text { Supply Chain } \\
\text { Operations }\end{array}$ & $\mathbf{5}$ & $\mathbf{7}$ & 7 \\
\hline $\begin{array}{c}\text { Customer } \\
\text { Fulfillment }\end{array}$ & $\mathbf{4}$ & 39 & 3 \\
\hline & 29 & & 29 \\
\hline
\end{tabular}

On the other hand, in the Flexible archetype, lead times are concise; a matter of urgency, besides the product is adapted to satisfy customer needs. This archetype is differentiated by the degree of product adaptability. Inditex balances this archetype by acquiring 'virgin' fabrics, untreated or undyed, to act quickly to changes in demand. Through this best practice, Inditex manages the highest level of market uncertainty cost because of the combination of both high demand variation and high-product renewal rate. Inditex also increases SC flexibility with its highly automated -specialised by garment- factories with lower utilisation toleration, to react to unexpected demand faster than rivals.

It also has invested heavily in setting up automated machinery for its manufacturing process and an integrated communications system that supports real-time sales and customer feedback data. This automation delivers flexibility and enables designers to modify an existing design or create new ones based on the daily transmission of information on the latest trend and sales. 
$H \& M$ : It balances the fast and efficient archetypes (see Figure 7) in which price is the main attribute. Unlike Inditex, who is less interested in having the lowest costs but maximising revenues, for $\mathrm{H} \& \mathrm{M}$, the focus is to maximise productivity and get the lowest costs to achieve the best prices. Its supplier management approach is opportunistic, that is, to take advantage of better costs, always thanks to the production offices located in different countries where their leading suppliers are.

Figure 7 Balance of SC archetypes for H\&M (see online version for colours)

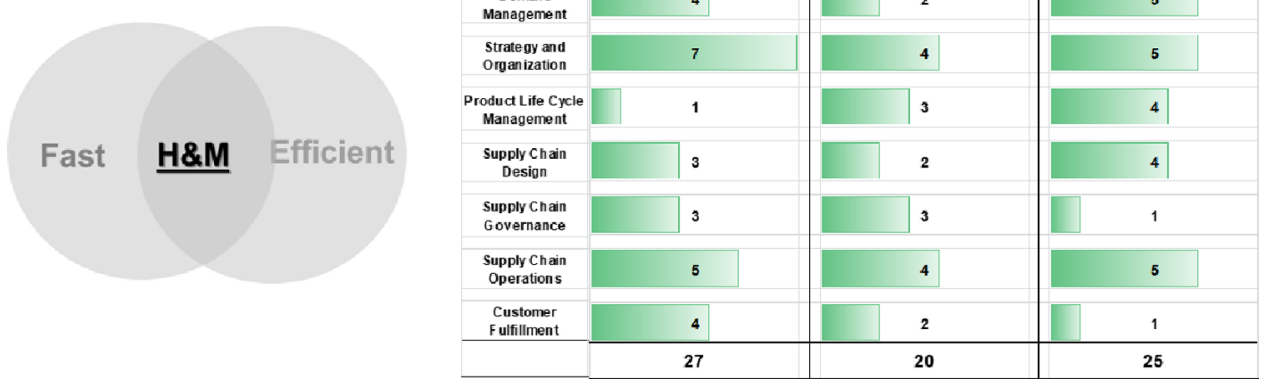

Nike: It balances between fast and flexible archetypes, as in Figure 8. Nike, having the innovation as the product promise, must align the whole network to this chain, because it not only sells fashion for sports but fashion with technology. For example, the use of Flyknit technology that corresponds to the fast archetype, while the firm is always trying to improve SC flexibility to address the uncertain outcomes of sporting events.

Figure 8 Balance of SC archetypes for Nike (see online version for colours)

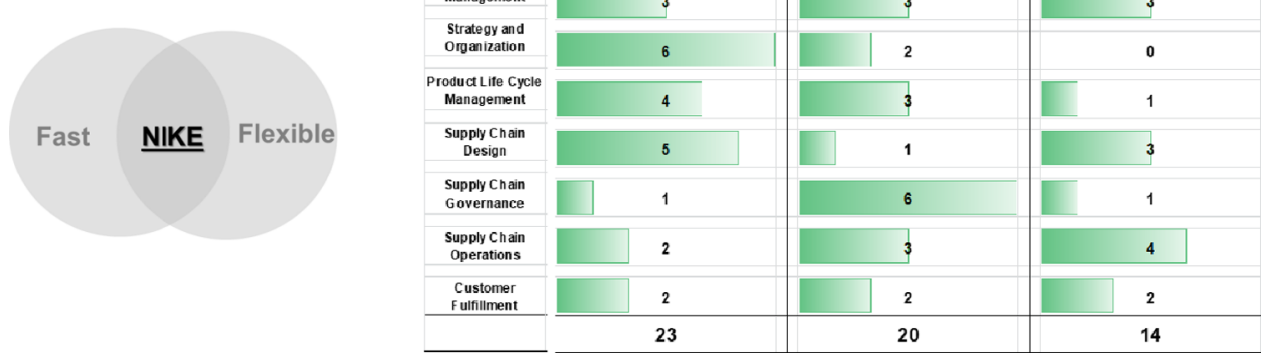

\section{Conclusion}

What makes different the apparel industry and the way its SC should be managed is the characteristic of the fickle demand, with an impulsive consumer that follows trends, and products with a very short life cycle, where responsiveness is a synonym of value. Competitiveness goes far beyond the management of a single company or even an SC but passes through the management of the whole supply network (Brun and Castelli, 2008). 
After reviewing the literature, it can be said that ambidexterity is a key to compete in an industry like the apparel since it is demanding to exploit the current resources to meet the demand (responsiveness), while exploration proposes innovative ways to manage the SC network. In the apparel industry, visionary and ambidextrous leaders are necessary to create and maintain relationships in this supply network to successfully compete. On the other hand, the role of the store manager becomes vital for Inditex and H\&M since they collect and feed SC with soft data (information about things that are difficult to measure, such as people's opinions or feelings).

All the previous were developed to achieve superior visibility through ambidexterity. For example, on orders status can have positive effects in terms of reducing internal logistics delays, due to improved planning, material handling, and transportation activities (Caridi et al., 2013).

In any industry, an equivalence to be ambidextrous is the handling and balance of trade-offs, but in the apparel industry, these trade-offs are more noticeable due to the nature of the goods, which, in a metaphorical way, may be called perishable goods. There are several trade-offs latent in this industry, for example, short-term vs. global margin in the long term; savings and lower costs vs. better quality and more variety; shocking marketing vs. speed, responsiveness, and flexibility to assimilate the latest trends.

Ambidexterity is notorious in the industry when it comes to the online distribution channel. For example, Nike and Inditex exploit their channels (brand websites) but also explore the possibility of distribution through e-commerce giant Alibaba, luxury webpage 'Tall'. This prevails them to effectively manage their inventory to meet the demand for that second channel that they do not own. Similarly, they should control very carefully the logistics costs, so the margins are achieved; besides, commissions are paid to Alibaba.

After analysing the three cases in the apparel industry, it can be said that it is easier to handle ambidexterity and develop a more favourable setting for innovation in the SC when it is vertically integrated as the case of Inditex. Thus, decisions along the chain depend on the brand and so can innovate and explore to gain both higher efficiency and responsiveness at every stage of the process.

One of the main obstacles to developing this research was the lack of literature linking the issues of SC and ambidexterity. If the reader intends to conduct a similar research on ambidexterity, it should bear in mind that will probably have to do the literature review in each topic separately. Afterward, prepare an analysis and integration work to link the subjects, to generate new knowledge and get findings.

\section{Acknowledgements}

The authors want to thank Tecnologico de Monterrey and CONACyT for financial support to develop this research activity. We also thank the two reviewers who provided insightful recommendations to improve this work.

\section{References}

Abernathy, F.H., Volpe, A. and Weil, D. (2006) 'The future of the apparel and textile industries: Prospects and choices for public and private actors', Environment and Planning A, Vol. 38, pp.2207-2232, doi: 10.1068/a38114. 
Anbanandam, R., Banwet, D.K. and Shankar, R. (2011) 'Evaluation of supply chain collaboration: a case of apparel retail industry in India', International Journal of Productivity and Performance Management, Vol. 60, No. 2, pp.82-98, doi: 10.1108/17410401111101449.

Aoki, M. and Aoki, M. (2014) 'Toward an economic model of the Japanese Firm', Comparative Institutional Analysis, pp.315-341. doi: 10.4337/9781783476213.00029.

Aravind Raj, S., Jayakrishna, K. and Vimal, K.E.K. (2018) 'Modelling the metrics of leagile supply chain and leagility evaluation', International Journal of Agile Systems and Management, Vol. 11, No. 2, pp.179-202, doi: 10.1504/IJASM.2018.10013698.

Aronow, S., Ennis, K. and Romano, J. (2018) The Gartner supply chain top 25 for 2018, Report G00351344, Gartner, https://www.gartner.com/en/documents/3875506/the-gartner-supplychain-top-25-for-2018

Blome, C., Schoenherr, T. and Kaesser, M. (2013) 'Ambidextrous governance in supply chains: the impact on innovation and cost performance', Journal of Supply Chain Management, Vol. 49, No. 4, pp.59-80, doi: https://doi.org/10.1111/jscm.12033.

Brun, A. and Castelli, C. (2008) 'Supply chain strategy in the fashion industry: developing a portfolio model depending on product, retail channel and brand', International Journal of Production Economics, Vol. 116, No. 2, pp.169-181, doi: 10.1016/j.ijpe.2008.09.011.

Byoungho, J., Hyo Jung, C., Matthews, D.R. and Gupta, M. (2012) 'Chapter 11. fast fashion business model: what, why and how?', Fashion Supply Chain Management, pp.193-211.

Cao, N. (2008) 'How are supply chains coordinated?: An empirical observation in textile-apparel businesses', Journal of Fashion Marketing and Management, Vol. 12, no. 3, pp.384-397.

Caridi, M., Perego, A. and Tumino, A. (2013),'Measuring supply chain visibility in the apparel industry', Benchmarking: An International Journal, Vol. 20 No. 1, pp.25-44, https://doi.org/ $10.1108 / 14635771311299470$

Chaturvedi, R. and Gupta, V. (2005) SCM and ERP Software Implementation at Nike - From Failure to Success, IBS Center for Management Research, pp.1-20.

Chiu, Y.C. (2014) 'Balancing exploration and exploitation in supply chain portfolios', IEEE Transactions on Engineering Management, Vol. 61, No. 1, pp.18-27, doi: 10.1109/TEM.2013.2280583.

Dari, L. and Paché, G. (2013) 'Contemporary fashion supply chains - under the control of style agencies?', International Business Research, Vol. 6, No. 5, pp.17-29, doi: 10.5539/ibr.v6n5p17.

Fromartz, S. (2010) 'Cinco compañías, cinco estrategias, cinco ejemplos de transformación', Harvard Deusto Business Review, May, pp.11-16.

Ganesan, S., George, M., Jap, S., Palmatier, R.W. and Weitz, B. (2009) 'Supply chain management and retailer performance: emerging trends, issues, and implications for research practice', Journal of Retailing, Vol. 85, No. 1, pp.84-94, doi: 10.1016/j.jretai.2008.12.001.

H\&M (2017) About H\&M, 2017, Available at: http://about.hm.com/en/About.html (Accessed 5 May, 2017).

Harris, G. A. (2007) Alignment of Supply Chain Strategy with Product Characteristics, ProQuest Dissertations and Theses, The University of Alabama in Hunstville, Available at: http://search.proquest.com/docview/304783126? accountid=7374

Hernández-Espallardo, M., Sánchez-Pérez, M. and Segovia-López, C. (2011) 'Exploitation- and exploration-based innovations: the role of knowledge in inter-firm relationships with distributors', Technovation, Vol. 31, Nos. 5-6, pp.203-215, doi: 10.1016/ j.technovation.2011.01.007.

Im, G. and Rai, A. (2008) 'Knowledge sharing ambidexterity in long-term interorganizational relationships', Management Science, Vol. 54, No. 7, pp.1281-1296, doi: 10.1287/ mnsc.1080.0902.

Inditex (2018) Inditex at a Glance, 2018, Available at: https://www.inditex.com/en/about-us/whowe-are (Accessed 11 November, 2018). 
Jakhar, S.K. and Barua, M.K. (2013) 'Supply chain agility for firm's performance: a study of textile-apparel-retail supply chain network', International Journal of Agile Systems and Management, Vol. 6, No. 3, pp.215-231.

Kauppila, O. (2007) 'Towards a Network Model of Ambidexterity', 17th Nordic Workshop on Interorganisational Research, 16-18 August, 2007, Turku, Finland.

Kim, B. (2013) 'Competitive priorities and supply chain strategy in the fashion industry', Qualitative Market Research, Vol. 16, No. 2, pp.214-242, doi: 10.1108/13522751311317602.

Kristal, M.M., Huang, X. and Roth, A.V. (2010) 'The effect of an ambidextrous supply chain strategy on combinative competitive capabilities and business performance', Journal of Operations Management, Elsevier B.V., Vol. 28, No. 5, pp.415-429, doi: 10.1016/j.jom.2009.12.002.

Kumar, S. (2008) 'Outsourcing strategies for apparel manufacture: a case study', Journal of Manufacturing Technology Management, 19, No. 1, pp.73-91.

MacCarthy, B.L. and Jayarathne, P.G.S.A. (2013) 'Supply network structures in the international clothing industry: differences across retailer types', International Journal of Operations \& Production Management, Vol. 33, No. 7, pp.858-886.

Man, L. (2009) 'Time makes a difference: insights from Zara's success', 2009 IEEE/INFORMS International Conference on Service Operations, Logistics and Informatics, 22-24 July, 2009, Chicago, Illinois, USA, pp.365-370.

Mavengere, N.B. (2013) 'Information technology role in supply chain's strategic agility', International Journal of Agile Systems and Management, Vol. 6, No. 1, pp.7-24, doi: https://doi.org/10.1504/IJASM.2013.052209.

Meichtry, S. (2007) 'Benetton picks up the fashion pace', Wall Street Journal - Eastern Edition, Vol. 249, No. 83, pp.B1-B2.

Moynian, P. and Dai, W. (2011) 'Agile supply chain management: a services system approach', International Journal of Agile Systems and Management, Vol. 4, No. 3, pp.280-300, doi: https://doi.org/10.1504/IJASM.2011.040519.

Mustafid, Karimariza, S.A. and Jie, F. (2018) 'Supply chain agility information systems with key factors for fashion industry competitiveness', International Journal of Agile Systems and Management, Vol. 11, No. 1, pp.1-22, doi: https://doi.org/10.1504/IJASM.2018.091352.

Ngai, E., Peng, S., Alexander, P. and Moon, K. (2014) 'Decision support and intelligent systems in the textile and apparel supply chain: an academic review of research articles', Expert Systems with Applications, Elsevier Ltd., Vol. 41, No. 1, pp.81-91, doi: 10.1016/j.eswa.2013.07.013.

Nike (2012) Nike Partners with Llamasoft for Sustainable Supply Chain Innovation [online], http://news.nike.com/news/nike-partners-with-llama (Accessed 1 April, 2017).

Nike (2015) Nike Supply Chain Disclosure, [online] http://help-en-us.nike.com/app/answers/ detail/arti (Accessed 6 April, 2017).

O'Reilly III, C.A. and Tushman, M.L. (2004) 'The ambidextrous organization', Harvard Business Review, Vol. 82, No. 4, pp.74-81.

Perez, H.D. (2013) Supply Chain Roadmap: Aligning Supply Chain with Business Strategy, 1st ed., Createspace Independent Pub.

Roth, A.V. (1996) 'Achieving strategic agility through economies of knowledge', Strategy and Leadership, Vol. 24, No. 2, pp.30-36.

Sidhu, J.S., Commandeur, H.R. and Volberda, H.W. (2007) 'The multifaceted nature of exploration and exploitation: value of supply, demand, and spatial search for innovation', Organization Science, Vol. 18, No. 1, pp.20-38, doi: 10.1287/orsc.1060.0212.

Simatupang, T.M. and Sridharan, R. (2002) 'The collaborative supply chain', The International Journal of Logistics Management, Vol. 13, No. 1, pp.15-30, doi: http://dx.doi.org/ 10.1108/MRR-09-2015-0216 
Stevenson, M. (2013) 'The role of services in flexible supply chains: an exploratory study', International Journal of Agile Systems and Management, Vol. 6, No. 4, pp.307-323, doi: https://doi.org/10.1504/IJASM.2013.058200

Thorbeck, J. (2014) 'The Zara Gap: retail's big arbitrage', Sourcing Journal, Available at: https://sourcingjournal.com/topics/retail/zara-gap-retails-big-arbitrage-18976/

Tokman, M., Richey R.G., Marino, L.D. and Weaver, K.M. (2007) 'Exploration, exploitation and satisfaction in supply chain portfolio strategy', Journal of Business Logistics, Vol. 28, No. 1, pp.25-56, doi: https://doi.org/10.1002/j.2158-1592.2007.tb00231.x

Uyterhoeven, H.E.R. (1993) Phil Knight Managing Nike's Transformation, Harvard Business School Publishing, Boston, MA, USA.

van Dijk, B. (2013) A.T. Kearney - Winning Supply Chain Integrate Today's Capabilities with Tomorrow's Goals, Available at: http://www.atkearney.dk//site-search?q=AESC\&submit $=$ Search website

Vogel, L. and Ramallo Garcia, A. (2012) Story: Nike's Gameplan for Growth that's Good for All, Available at: http://www.managementexchange.com/story/nike's-gameplan-growth-that'sgood-all (Accessed 4 April, 2016).

Wells, J.R. and Danskin, G. (2013) Inditex: 2012, Harvard Business School Publishing, Boston, MA, USA.

Yan, G., Qi, X. and Xinping, S. (2009) 'Research on the information integration framework of apparel supply chain based on Web Service', Service Operations, Logistics and Informatics, 2009. SOLI '09 IEEE/INFORMS International Conference, IEEE, 22-24 July 2009, Chicago, IL, USA, pp.598-603, doi: 10.1109/SOLI.2009.5204004.

Zhang, Q. (2008a) 'Analysis on the successful case of efficient supply chain in ZARA', Wireless Communications, Networking and Mobile Computing. WiCOM '08. 4th International Conference, IEEE, Dalian, China, pp.1-4, doi: 10.1109/WiCom.2008.1579.

Zhang, Q. (2008b) 'What and how can we learn from ZARA', Proceedings of 2008 IEEE International Conference on Service Operations and Logistics, and Informatics, IEEE/SOLI 2008, IEEE, Beijing, China, pp 2464-2468, doi: 10.1109/SOLI.2008.4682950

\section{Appendix 1}

One dimension of the AAASC evaluation tool (see online version for colours).

\begin{tabular}{l}
\hline \hline TOOL CONTENTS \\
\hline Cover Page \\
Instructions \\
Status of Evaluation \\
1.- Demand Management Form \\
2.- Strategy and Organization Form \\
3.- Product Life Cycle Form \\
4.- Supply Chain Design Form \\
5.- Supply Chain Governance Form \\
6.- Supply Chain Operations Form \\
7.- Customer Fulfillment Form \\
Output \\
Conclusions
\end{tabular}

\begin{tabular}{|c|c|c|c|c|}
\hline DIMENSION & $\begin{array}{c}\text { NO } \\
\text { PRACTICE }\end{array}$ & EXPLOIT & EXPLORE & AMBIDEXTROUS \\
\hline $\begin{array}{c}\text { Demand } \\
\text { Management }\end{array}$ & N/A & 3 & 4 & 4 \\
\hline $\begin{array}{c}\text { Strategy and } \\
\text { Organization }\end{array}$ & N/A & 4 & 8 & 4 \\
\hline $\begin{array}{c}\text { Product Life Cycle } \\
\text { Management }\end{array}$ & N/A & 3 & 3 & 1 \\
\hline $\begin{array}{c}\text { Supply Chain } \\
\text { Dosign }\end{array}$ & N/A & 2 & 5 & 5 \\
\hline $\begin{array}{c}\text { Supply Chain } \\
\text { Governance }\end{array}$ & N/A & 5 & 5 & 5 \\
\hline $\begin{array}{c}\text { Supply Chain } \\
\text { Operations }\end{array}$ & N/A & 8 & 7 & 7 \\
\hline $\begin{array}{c}\text { Customer } \\
\text { Fulfillment }\end{array}$ & N/A & 4 & 7 & 3 \\
\hline & 29 & 39 & 29 \\
\hline
\end{tabular}




\section{Appendix 1 (continued)}

One dimension of the AAASC evaluation tool (see online version for colours).

\begin{tabular}{|c|c|c|c|c|c|}
\hline Dimension 1: Demand Management & & & & & \\
\hline Cover Page Tool Content & & & & & \\
\hline \multicolumn{6}{|l|}{$\begin{array}{l}\text { This dimension refers to the capabilities related to anticipating and prioritizing the customers needs, aligning these } \\
\text { needs with supply from internal and external resources, effectively plan for capacity and utilization (in terms of volumes } \\
\text { and time frames). Allocate the appropriate technology resources from the optimal delivery locations. }\end{array}$} \\
\hline & \multicolumn{5}{|c|}{ Number of Practices } \\
\hline 1.1 Platforms and Social Network & 0 & 1 & 2 & 3 & $4+$ \\
\hline $\begin{array}{l}\text { Platforms to buy from suppliers, programmed under actual customer demand rather than forecast. The SC also leverages social networks } \\
\text { anly to sense the demand. }\end{array}$ & & $\mathrm{x}$ & & & \\
\hline $\begin{array}{l}\text { Platforms that explores the nonstop flow of information from the POS (point of sale) conveying shopper desires and demands. Engages with } \\
\text { social media to understands its consumers and be highly sensitive to trends. }\end{array}$ & & $\mathrm{x}$ & & & \\
\hline $\begin{array}{l}\text { Platforms to exploit hard data (market specialists) and explore soft data (phone calls/emails with stores managers). Exploit the own social } \\
\text { networks (sense) while explore demand (shape) through knowledge/experience of other social network groups, e-g. Youtube. }\end{array}$ & & $\mathrm{x}$ & & & \\
\hline 1.2 Brands, locations, channels and tools & 0 & 1 & 2 & 3 & $4+$ \\
\hline $\begin{array}{l}\text { Acquisition of other brand stores including employees to exploit the demand according to the store location and leverage the demand } \\
\text { knowledge that they already have. The head office get reports about the stores sales and status to sense the demand. }\end{array}$ & & $\mathrm{x}$ & & & \\
\hline $\begin{array}{l}\text { Explore multiple brand portfolio to meet the demands of the segmented market. Use of innovative and advanced SC analytics to sense and } \\
\text { shape the demand }\end{array}$ & & $\mathrm{x}$ & & & \\
\hline $\begin{array}{l}\text { Exploit demand for basics in small suburbs while explore the demand for high fashionable garments in the big cities. Explore different } \\
\text { channels for customer feedback data, while exploit real-time sales information. This enables to shape, sense and manage the demand since } \\
\text { designers can modify an existing design or create new ones. }\end{array}$ & & $\mathrm{x}$ & & & \\
\hline 1.3 Relationships network and flow/type of information & 0 & 1 & 2 & 3 & $4+$ \\
\hline $\begin{array}{l}\text { Exploit contractual relationships with suppliers to get supplementary orders out into the stores within just a few weeks when goods are selling } \\
\text { well. The office sometimes calls the stores to get some informal and "soft" information. }\end{array}$ & & $x$ & & & \\
\hline $\begin{array}{l}\text { Explore the network to add new partners as soon as customers showed demand for new products and services. The store managers elaborate } \\
\text { pre-design reports by the planners in the office and headquarters. }\end{array}$ & $x$ & & & & \\
\hline $\begin{array}{l}\text { Daily communication, both formal and informal is maintained between the office and all the stores. Exploit the demand in the owned stores } \\
\text { while explare the possibility to increase demand through large specialty distributors (for example "foot locker") }\end{array}$ & & $x$ & & & \\
\hline 1.4 Marketing and Design & 0 & 1 & 2 & 3 & $4+$ \\
\hline $\begin{array}{l}\text { Exploit extensive marketing to influnece events that shape demand such as runaways, sport events, etc. Exploit awn designs. There is lawer } \\
\text { level of flexibility in the supply chain. }\end{array}$ & $\mathrm{x}$ & & & & \\
\hline $\begin{array}{l}\text { Explore negative inventories: artificial scarcity to encourage faddish buying behaivor and demand. Improve and explore the supply chain } \\
\text { flexibility to address the uncertain outcomes of fashion and sports events. }\end{array}$ & & & $x$ & & \\
\hline $\begin{array}{l}\text { Exploit traditional marketing and the brand's own designs while explore innovative strategies to encourage the demand, for example scarcity } \\
\text { in the stores and jaint venture collabarations with designers to explore and exploit the demand for the designer's designs. }\end{array}$ & $x$ & & & & \\
\hline 1.5 Speed and size of deliveries & 0 & 1 & 2 & 3 & $4+$ \\
\hline Focus in deliver as much styles and pieces as passible in the lowest lead time possible. & $\mathrm{x}$ & & & & \\
\hline $\begin{array}{l}\text { Explore small batches of production to measure demand and enable fexibility. Instead of more quantity of an style, the company produces } \\
\text { more styles }\end{array}$ & $x$ & & & & \\
\hline Explare right trends while exploit the speed of delivery capability and supply the garments to the stores manths before its competitors & & $\mathrm{x}$ & & & \\
\hline
\end{tabular}

